\title{
Characteristics of a Hybrid Detector Combined with a Perovskite Active Layer for Indirect X-ray Detection
}

\author{
Hailiang Liu, Jehoon Lee and Jungwon Kang *(D) \\ Department of Electronic and Electrical Engineering, Dankook University, Gyeonggi-do 16890, Korea; \\ liuhailiang107@gmail.com (H.L.); usyj0512@gmail.com (J.L.) \\ * Correspondence: jkang@dankook.ac.kr; Tel.: +82-31-8005-3624
}

Received: 27 October 2020; Accepted: 28 November 2020; Published: 1 December 2020

\begin{abstract}
In this study, we investigated the characteristics of an organic-inorganic hybrid indirect-type $\mathrm{X}$-ray detector with a $\mathrm{CH}_{3} \mathrm{NH}_{3} \mathrm{PbI}_{3}\left(\mathrm{MAPbI}_{3}\right)$ perovskite active layer. A layer with a thickness of $192 \mathrm{~nm}$ annealed at $100^{\circ} \mathrm{C}$ showed higher absorption, higher crystallinity, and lower surface roughness than did perovskite layers made under different conditions. In the indirect $X$-ray detector, a scintillator coupled with the detector to convert X-ray photons to visible photons, and the converted photons were absorbed by the active layer to generate charge carriers. The detector with the optimized $\mathrm{MAPbI}_{3}$ (192 nm thick and $100{ }^{\circ} \mathrm{C}$ annealing condition) active layer was coupled with a CsI(Tl) scintillator which consisted of $400 \mu \mathrm{m}$ thick CsI and $0.5 \mathrm{~mm}$ thick $\mathrm{Al}$, and achieved the highest sensitivity, i.e., $2.84 \mathrm{~mA} / \mathrm{Gy} \cdot \mathrm{cm}^{2}$. In addition, the highest short-circuit current density (JSC), i.e., $18.78 \mathrm{~mA} / \mathrm{cm}^{2}$, and the highest mobility, i.e., $2.83 \times 10^{-4} \mathrm{~cm}^{2} / \mathrm{V} \cdot \mathrm{s}$, were obtained from the same detector without the CsI(Tl) scintillator.
\end{abstract}

Keywords: perovskite active layer; indirect X-ray detector; hybrid detector

\section{Introduction}

Metal-halide perovskites are promising materials for optoelectronic and photonic devices, such as solar cells [1,2], photodetectors [3,4], and light-emitting diodes [5,6], and their applications are expanding to field-effect transistors $[7,8]$. These materials have many interesting properties, such as low-cost solution processability [9], highly efficient light absorption [10], long electron-hole diffusion length [11], and high carrier mobility [12]. Among many applications, perovskite solar cells have shown impressive results, with efficiencies of over $20 \%$ after just a few years of tremendous effort [13,14]. Methylammonium lead iodide $\left(\mathrm{MAPbI}_{3}\right)$ is not only the most basic material but also the most widely used perovskite material as an active layer for various devices. This material can also be applied to the active layer of $X$-ray radiation detectors in fields such as security and health care [15-18]. Recently, Yakunin et al. reported a $\mathrm{MAPbI}_{3}$-based p-i-n photodiode with a sensitivity of $0.03 \mathrm{~mA} / \mathrm{Gy} \cdot \mathrm{cm}^{2}$ [19]. Shrestha et al. observed excellent performance for a direct-conversion X-ray detector based on millimeter-thick $\mathrm{MAPbI}_{3}$ with a sensitivity of $0.25 \mathrm{~mA} / \mathrm{Gy} \cdot \mathrm{cm}^{2}$ [20]. If the detection sensitivity and manufacturing process are improved, $\mathrm{MAPbI}_{3}$ could be a promising candidate for an active layer applied to X-ray detectors.

Recent studies have emphasized the importance of the perovskite morphology [21,22] and crystal orientation $[23,24]$ for the performance of perovskite-applied devices. The smoother surface, high crystallinity, and preferred crystal orientation of the perovskite film generally lead to high photocurrents. In addition, the photovoltaic absorber $\mathrm{MAPbI}_{3}$ shows the $\mathrm{CH}_{3} \mathrm{NH}_{3}$ molecular motion, which can induce a dynamic bandgap, could prevent carrier recombination, and could help excitons to separate, thereby improving their efficiencies in optoelectronic devices [25]. A slightly larger grain size and higher crystallinity of $\mathrm{MAPbI}_{3}$ helped reduce the trap density and increase the photocurrent 
of devices. Moreover, solvent annealing helps to obtain a larger $\mathrm{MAPbI}_{3}$ grain size and crystallinity, which could lead to significant improvements in material electronic properties and photovoltaic device performance [26]. Adjusting the thickness of the perovskite layer was critical to determine the influence of its morphology [27]. Although the efficiencies of perovskite materials in optoelectronic devices have been extensively improved, no systematic research has been undertaken to determine the influence of the annealing temperature and thickness of the perovskite layer on its surface morphology and sensitivity, especially concerning the performance of $X$-ray devices.

In this work, we reported a highly sensitive $X$-ray detector with a thin perovskite active layer for indirect $\mathrm{X}$-ray detection under $63 \mathrm{keV} \mathrm{X}$-ray irradiation conditions. The effects of the annealing temperature and film thickness of the perovskite film on the morphology, light absorption and crystal orientation of the film were investigated, and finally, the influence of these parameters on the operating characteristics of a detector with a perovskite layer was investigated. We analyzed the crystal orientation of the perovskite film using the X-ray diffraction method (XRD, Rigaku D/Max-2500) and light absorbance using UV-Visible absorption spectroscopy (UV-VIS, Optizen 2120UV). The thickness and surface roughness of the perovskite film were measured using scanning electron microscopy (SEM, Hitachi S-4700) and atomic-force microscopy (AFM, Park Systems XE-150). When the perovskite detector was decoupled with a $\mathrm{CsI}(\mathrm{Tl})$ scintillator, it worked like a photodetector or solar cell, and the series resistance $\left(\mathrm{R}_{\mathrm{S}}\right)$ and short-circuit current $\left(\mathrm{J}_{S C}\right)$ were extracted through the current density-voltage $(\mathrm{J}-\mathrm{V})$ characteristics. When the perovskite detector was coupled with the CsI(Tl) scintillator, it worked like an X-ray detector, and the X-ray parameters were extracted under X-ray irradiation. The CsI(Tl) scintillator consisting of $400 \mu \mathrm{m}$ thick CsI and $0.5 \mathrm{~mm}$ thick $\mathrm{Al}$ showed a maximum emission peak at $550 \mathrm{~nm}$, matching with the absorption spectrum of the $\mathrm{MAPbI}_{3}$ active layer (as shown in Figure S1 in Supplementary Materials). The CsI(Tl) scintillator served to convert incident X-ray photons into visible photons, and the converted visible light photons were absorbed by the perovskite active layer to create charge carriers.

Figure 1 shows the energy-band diagram of the proposed detector with the $\mathrm{MAPbI}_{3}$ active layer. The visible photons converted by the scintillator were absorbed by the $\mathrm{MAPbI}_{3}$ to create electron-hole pairs that were separated in the active layer according to the energy band position. The electrons were transferred to the indium-tin oxide (ITO) anode, where the resulting in charge was collected. As the electron transport layer (ETL), (6,6)-phenyl-C71-butyric acid methyl ester (PCBM) was used, while poly(3,4-ethylenedioxythiophene) polystyrene sulfonate (PEDOT:PSS) was used as the hole transport layer (HTL), which helped the movement of the electrons and holes to the electrodes, respectively.

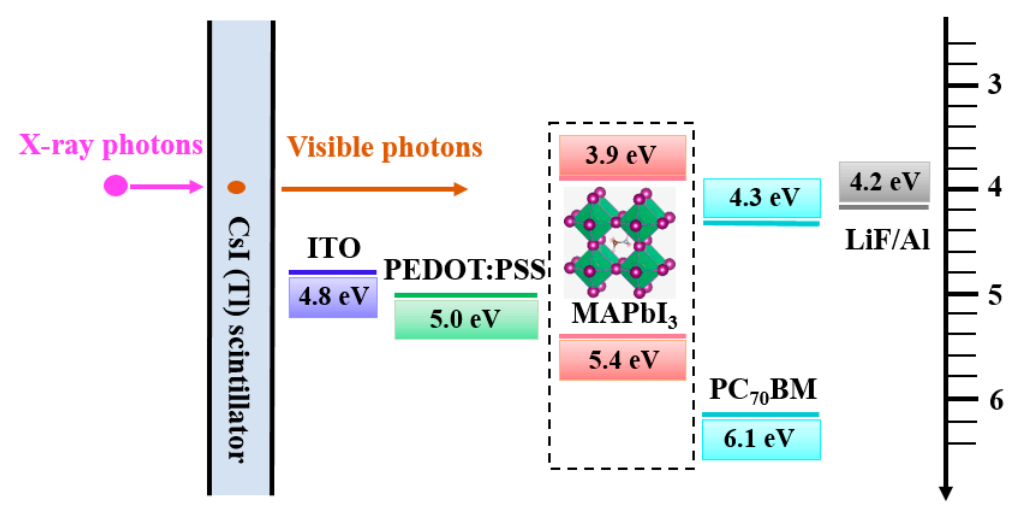

Figure 1. Energy-band diagram of the proposed detector with perovskite active layer. 


\section{Experimental Preparations}

\subsection{Synthesis of $M A P b I_{3}$ Precursor Solution}

The compounds iodide (MAI, Aldrich 793493), lead (II) iodide ( $\mathrm{PbI}_{2}$, Aldrich 203602), $\gamma$-butyrolactone (GBL, Aldrich H7629), dimethyl sulfoxide (DMSO, Aldrich D8418) and chlorobenzene (Anhydrous, Aldrich 284513) were used as received. We dissolved MAI (159 mg) and $\mathrm{PbI}_{2}(461 \mathrm{mg})$ at 1:1 (mol/mol) in GBL $(700 \mu \mathrm{L})$ and DMSO $(300 \mu \mathrm{L})$ at 7:3 (vol/vol) and stirred it at $70{ }^{\circ} \mathrm{C}$ for $12 \mathrm{~h}$. Finally, we got the full-grown mature precursor solution. The complete solvent engineering procedure for the perovskite precursor solution is shown in Figure 2. The perovskite precursor solution was prepared referring to the method reported in [28].

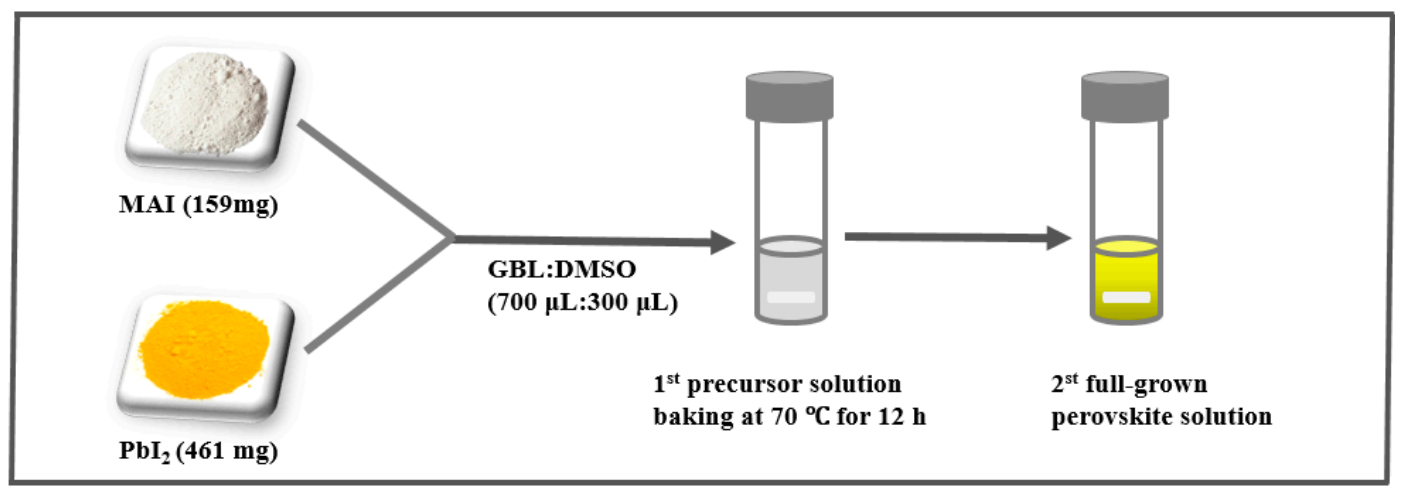

Figure 2. Solvent engineering procedure for the preparation of the perovskite precursor solution.

\subsection{Devices Fabrication}

Figure 3a shows a schematic diagram of the fabricated detector, which consisted of glass/ITO/PEDOT:PSS/MAPbI ${ }_{3}$ perovskite active layer/PCBM/LiF/Al. Figure $3 \mathrm{~b}$ shows the fabrication procedure of the proposed detector with the perovskite active layer and the solution process to form the layer. An indium-tin-oxide (ITO) anode $(150 \mathrm{~nm})$ on a glass substrate was patterned and then cleaned sequentially for $5 \mathrm{~min}$ using sonification treatment of acetone, methanol and IPA. The glass substrate was dried in a vacuum oven at $100{ }^{\circ} \mathrm{C}$ for $10 \mathrm{~min}$. A charge transport layer of poly(3,4-ethylene dioxythiophene):poly (styrene sulfonate) (PEDOT:PSS, Clevios P VP Al4083) layer was spin-coated on the cleaned glass substrate at $3000 \mathrm{rpm}$ for $30 \mathrm{~s}$, and then annealed at $150{ }^{\circ} \mathrm{C}$ for $30 \mathrm{~min}$. The hickness of the PEDOT:PSS layer as the hole transport layer (HTL) was about $30 \mathrm{~nm}$. The prepared $\mathrm{MAPbI}_{3}$ solution was spin-coated on the PEDOT:PSS layer at various spin-rates of 3000, 3500, 4000, and $4500 \mathrm{rpm}$ for $40 \mathrm{~s}$. Before the end of the spin-coating process, $200 \mu \mathrm{L}$ chlorobenzene solvent was pipetted onto the substrate to wash off the DMSO solvent of the perovskite wet film and induce rapid crystallization. After the spin-coating process, the perovskite film was baked at $100{ }^{\circ} \mathrm{C}$ for $10 \mathrm{~min}$. Then, $20 \mathrm{mg}$ of phenyl-C71-butyric acid methyl ester (PCBM, Emindex 609771-63-3) powder was dissolved in $1 \mathrm{~mL}$ of chlorobenzene and stirred at $60{ }^{\circ} \mathrm{C}$ for $3 \mathrm{~h}$. The PCBM solution was spin-coated onto the perovskite layer at a spin rate of $1100 \mathrm{rpm}$, and the perovskite was baked at $100{ }^{\circ} \mathrm{C}$ for $10 \mathrm{~min}$. The thickness of the PCBM layer as the electron transport layer (ETL) was about $80 \mathrm{~nm}$. After forming the PCBM layer, the aging time of the sample was $12 \mathrm{~h}$. LiF/Al as the cathode, consisting of $5 \mathrm{~nm}$ thick LiF and $120 \mathrm{~nm}$ thick $\mathrm{Al}$, was deposited on the PCBM layer in a thermal evaporation chamber. The manufactured detector was encapsulated with a glass cover to prevent it from being exposed to air. Finally, the detector with four effective areas of $0.04 \mathrm{~mm}^{2}$ was successfully fabricated. 


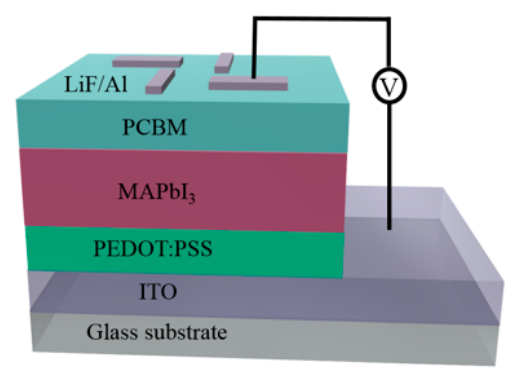

(a)

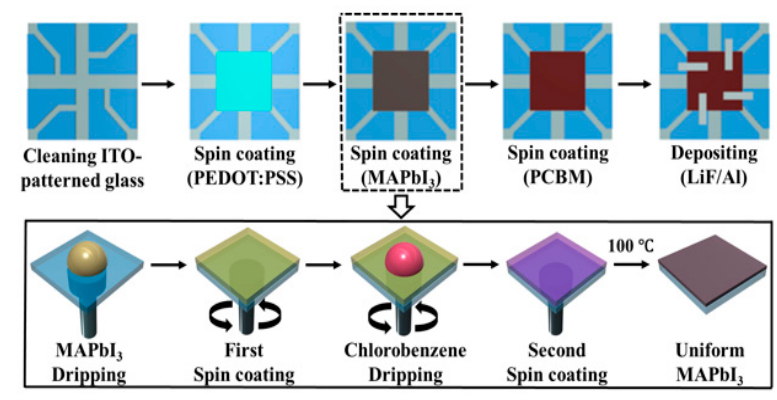

(b)

Figure 3. (a) Schematics of the constructed bulk heterojunction preoskite device, (b) Fabrication procedure of the perovskite detector and solvent engineering procedure for preparing the uniform and dense perovskite film.

\subsection{Experimental Set-Up}

Figure 4 shows the experimental setup to evaluate the properties of the radiation detector with the perovskite active layer. It mainly consisted of three components: an X-ray generator (AJEX 2000H), a solar illumination simulator (San Ei Elec. XES-40S2-CE), and an electrometer (Keithley 2400) to measure the photocurrent.
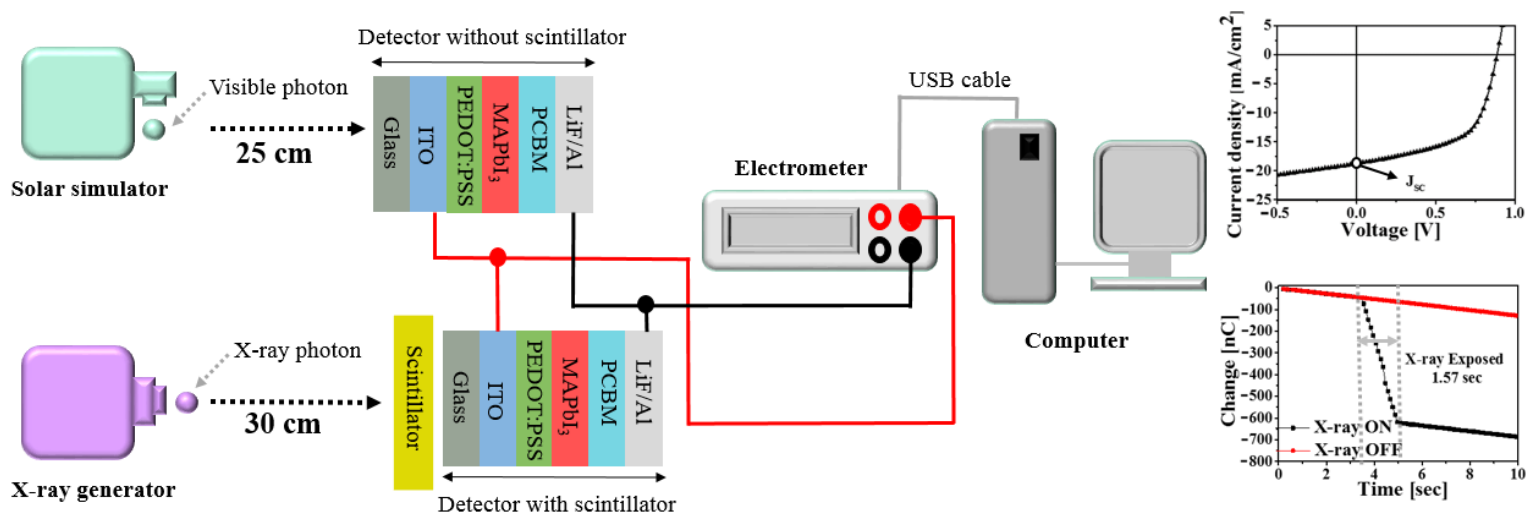

Figure 4. Schematic diagram of the experimental setup for measuring the parameters of the perovskite detector without and with the $\mathrm{CsI}(\mathrm{Tl})$ scintillator.

First, the characteristics of the detector without the $\mathrm{CsI}(\mathrm{Tl})$ scintillator were evaluated under the condition of exposure to the AM 1.5G filtered Xe lamp of the solar simulator, and the intensity of the exposed light was $100 \mathrm{~mW} / \mathrm{cm}^{2}$. The distance between the solar simulator and the detector was fixed at $25 \mathrm{~cm}$. The generated charges were collected by applying a bias of -1.0 to $1.0 \mathrm{~V}$. The various parameters, such as short-circuited current density $\left(\mathrm{J}_{\mathrm{SC}}\right)$ and series resistance $\left(\mathrm{R}_{\mathrm{S}}\right)$, were obtained from the J-V characteristics during the artificial solar irradiation. $\mathrm{JSC}_{\mathrm{SC}}$ is the current density as measured by the incident light when the detector was short-circuited, which could be extracted from the $0 \mathrm{~V}$ bias of the $\mathrm{J}-\mathrm{V}$ curve. $\mathrm{R}_{\mathrm{S}}$ is the resistance of the active layer outside its space-charge layer, in addition to the contact resistances of the metal electrodes to the active layer. They are crucial for the charge-carrier generation of the detector.

Second, for the X-ray detector measurement, we evaluated the perovskite detector combined with the $\mathrm{CsI}(\mathrm{Tl})$ scintillator under $\mathrm{X}$-ray exposure. For all experiments, the operation of the X-ray generator was fixed at $80 \mathrm{kVp}$ and $60 \mathrm{mAs}$, and it was irradiated for $1.57 \mathrm{~s}$. The distance between the $\mathrm{X}$-ray generator and the detector was $30 \mathrm{~cm}$. The exposure $\mathrm{X}$-ray dose was measured using an ion chamber (Capintec CII50) at the same distance. The absorbed dose was converted from X-ray exposure, which was $3.44 \mathrm{mGy}$. To collect the charge generated during X-ray exposure, a $0.6 \mathrm{~V}$ bias was applied between the cathode and anode of the detector. We calculated the radiation parameters 
during the $X$-ray exposure, that is, the collected current density (CCD) during the X-ray irradiation on-condition and the dark current density (DCD) during the X-ray irradiation off-condition were calculated by Equations (1), and (2), respectively. The sensitivity was calculated using Equation (3), which represented the generated current in proportion to the absorbed dose.

$$
\begin{gathered}
\operatorname{CCD}\left[\frac{\mu \mathrm{A}}{\mathrm{cm}^{2}}\right]=\frac{\text { Collected Current during } X-\text { ray ON }}{\text { Exposed Detection Area }} \\
\operatorname{DCD}\left[\frac{\mu \mathrm{A}}{\mathrm{cm}^{2}}\right]=\frac{\text { Collected Current during } X-\text { ray OFF }}{\text { Exposed Detection Area }} \\
\text { Sensitivity }\left[\frac{\mu \mathrm{A}}{\mathrm{mGy} \cdot \mathrm{cm}^{2}}\right]=\frac{\mathrm{CCD}-\mathrm{DCD}}{\text { Absorbed Dose }}
\end{gathered}
$$

\section{Results and Discussion}

We used X-ray diffraction (XRD) measurements to investigate the properties of the $192 \mathrm{~nm}$ thick $\mathrm{MAPbI}_{3}$ layer under different annealing temperatures $\left(60,80,100\right.$ and $\left.120^{\circ} \mathrm{C}\right)$, as shown in Figure $5 \mathrm{a}$. Noticeable diffraction peaks were observed depending on the annealing temperature. The XRD patterns were composed of two phases, i.e., $\mathrm{MAPbI}_{3}$ and $\mathrm{PbI}_{2}$. For the $\mathrm{PbI}_{2}$ phase, we assigned the peak at $12.21^{\circ}$ to the (001) plane. For the $\mathrm{MAPbI}_{3}$ phase, the peaks at $14.08,28.46,40.21$ and $43.31^{\circ}$ were respectively assigned to the (110), (220), (044) and (006) planes. The highest peak intensity of the perovskite layer was achieved at $100{ }^{\circ} \mathrm{C}$. As the annealing temperature of the perovskite increased, the rate of perovskite crystallization was similarly increased, and the crystallinity improved up to the optimal temperature of $100{ }^{\circ} \mathrm{C}$. However, when the annealing temperature exceeded the optimal temperature, i.e., up to $120^{\circ} \mathrm{C}$, the crystallinity dropped significantly, because the $\mathrm{MAPbI}_{3}$ was decomposed into $\mathrm{PbI}_{2}, \mathrm{CH}_{3} \mathrm{NH}_{2}$ and $\mathrm{HI}$ at an annealing temperature of $120^{\circ} \mathrm{C}$ [26].

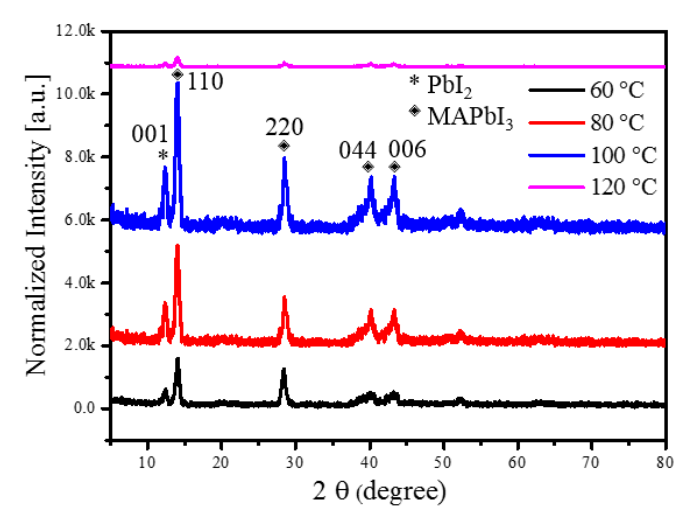

(a)

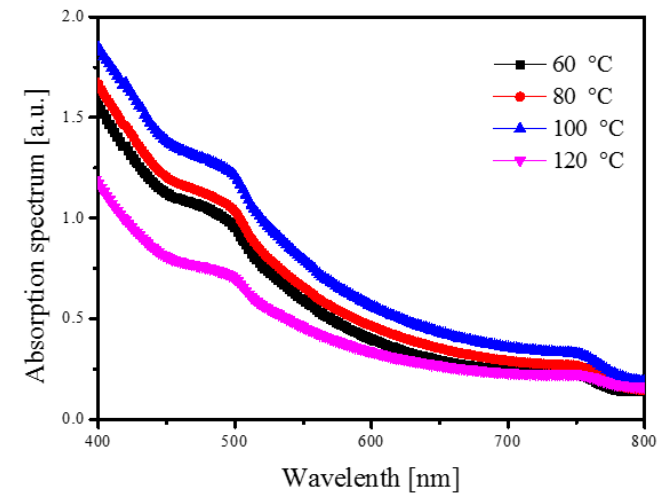

(b)

Figure 5. (a) XRD patterns and (b) absorption spectra of $192 \mathrm{~nm}$ thick $\mathrm{MAPbI}_{3}$ layer with different annealing temperatures.

Figure $5 \mathrm{~b}$ shows the absorption spectra of the $192 \mathrm{~nm}$ thick $\mathrm{MAPbI}_{3}$ layer with annealing temperatures of $60,80,100$, and $120^{\circ} \mathrm{C}$. It was clear that the absorption intensity increased as the annealing temperature increased from 60 to $100{ }^{\circ} \mathrm{C}$. When the annealing temperature reached $120^{\circ} \mathrm{C}$, the annealing temperature was too high, resulting in degradation in the perovskite layer. As a result, the absorption intensity decreased as the light-harvesting ability decreased. The result of the decrease of light absorption capacity was consistent with the result of XRD, which was caused by the decomposition of the $\mathrm{MAPbI}_{3}$ due to the high heating temperature.

To investigate the photovoltaic properties of the detectors based on a $\mathrm{MAPbI}_{3}$ layer under different annealing temperatures, we measured the current density-voltage $(\mathrm{J}-\mathrm{V})$ characteristics of the detector based on a $192 \mathrm{~nm}$ thick $\mathrm{MAPbI}_{3}$ layer, as shown in the Figure S4. The parameters including JSC, $\mathrm{R}_{\mathrm{S}}$, 
CCD and sensitivity of the detectors are listed in Table 1 . The device constructed with an annealing temperature of $60^{\circ} \mathrm{C}$ achieved $\mathrm{J}_{\mathrm{SC}}$ of $16.39 \mathrm{mAcm}^{-2}, \mathrm{R}_{\mathrm{S}}$ of $212.78 \Omega$, and sensitivity of $2.26 \mathrm{~mA} / \mathrm{Gycm}^{2}$. When the active layer was annealed at $100^{\circ} \mathrm{C}$, the device yielded an improved $\mathrm{J}_{\mathrm{SC}}$ of $18.78 \mathrm{mAcm}^{-2}$, $\mathrm{R}_{\mathrm{S}}$ of $172.23 \Omega$, and sensitivity of $2.84 \mathrm{~mA} / \mathrm{Gycm}^{2}$, i.e., $25 \%$ better sensitivity compared to the use of an active layer annealed at $60{ }^{\circ} \mathrm{C}$. In addition, to further observe the effect of different temperatures on the perovskite layer, the current density-voltage $(\mathrm{J}-\mathrm{V})$ curves of the detectors with different thicknesses of $\mathrm{MAPbI}_{3}$ active layer $(109,145$ and $215 \mathrm{~nm}$ ) were also measured (as depicted in Figures S2, S3 and S5 of Supplementary Materials). The parameters such as $\mathrm{J}_{S C}, \mathrm{R}_{\mathrm{S}}, \mathrm{CCD}$ and sensitivity of the detectors are listed in Table S1-S3 (see Supplementary Materials), respectively. About 10 detectors with the $\mathrm{MAPbI}_{3}$ active layer were manufactured to verify the reproducibility.

Table 1. $\mathrm{J}_{\mathrm{SC}}, \mathrm{R}_{\mathrm{S}}, \mathrm{CCD}$ and sensitivity of the detector based on $192 \mathrm{~nm}$ thick $\mathrm{MAPbI}_{3}$ layer at various annealing temperatures.

\begin{tabular}{ccccc}
\hline Temperature $\left[{ }^{\circ} \mathbf{C}\right]$ & Jsc $\left[\mathbf{m A} / \mathbf{c m}^{2}\right]$ & Rs $[\Omega]$ & CCD $\left[\boldsymbol{\mu A} / \mathbf{c m}^{2}\right]$ & Sensitivity $\left[\mathbf{m A} / \mathbf{G y} \cdot \mathbf{c m}^{2}\right]$ \\
\hline 60 & $16.39 \pm 0.65$ & $212.78 \pm 3.9$ & $8.78+0.14$ & $2.26 \pm 0.07$ \\
80 & $17.74 \pm 0.62$ & $181.72 \pm 3.8$ & $9.41+0.13$ & $2.43 \pm 0.06$ \\
100 & $18.78 \pm 0.58$ & $172.23 \pm 3.9$ & $10.88+0.13$ & $2.84 \pm 0.06$ \\
120 & $11.56 \pm 0.72$ & $298.87 \pm 3.8$ & $7.82+0.13$ & $1.99 \pm 0.08$ \\
\hline
\end{tabular}

Scanning electron microscopy (SEM) images of $\mathrm{MAPbI}_{3}$ films of different thicknesses grown on a glass/ITO/PEDOT: PSS stacked structure are shown in Figure 6a. The annealing temperature was fixed at $100{ }^{\circ} \mathrm{C}$. The $\mathrm{MAPbI}_{3}$ film thickness depended on the spin-coating speed. From the cross-sectional SEM images, we confirmed that $\mathrm{MAPbI}_{3}$ films that were 109,145, 192, or $215 \mathrm{~nm}$ thick were sequentially formed under spin rates of 3000, 3500, 4000, and $4500 \mathrm{rpm}$. To understand the effect of perovskite film thickness on the morphology, we used AFM analysis to evaluate the change in the topology of the perovskite films on the ITO-coated glass. Figure $6 \mathrm{~b}$ shows the topographical 3D images of the perovskite thin films. The RMS surface roughness (Rq) of $109 \mathrm{~nm}, 145 \mathrm{~nm}, 192 \mathrm{~nm}$, and $215 \mathrm{~nm}$ thick perovskite layers was $43.8 \mathrm{~nm}, 32.2 \mathrm{~nm}, 21.9 \mathrm{~nm}$, and $36.8 \mathrm{~nm}$, respectively. As the thickness of the perovskite film increased, the surface roughness decreased. This was because the presolution of $\mathrm{MAPbI}_{3}$ could grow more completely into a thin film. When the thickness increased to $215 \mathrm{~nm}$, the surface roughness increased; this was because some of the presolution could not react completely with an excessively thick $\mathrm{MAPbI}_{3}$ layer.

Figure 7a shows the XRD characteristics of $\mathrm{MAPbI}_{3}$ films with different thicknesses at an annealing temperature of $100^{\circ} \mathrm{C}$. For all $\mathrm{MAPbI}_{3}$ peaks, the (110) phase had the highest peak intensity, while the other (220), (044) and (006) phases had relatively low peak intensities. It was confirmed that the polycrystalline $\mathrm{MAPbI}_{3}$ film had a dominant orientation in the (110) phase. As the thickness of the $\mathrm{MAPbI}_{3}$ film increased, the peak intensity of the (110) phase increased, and it was confirmed that the change in the film thickness influenced the crystallinity of the perovskite. Considering the structural stability for the (110) orientation, the 192-nm thick $\mathrm{MAPbI}_{3}$ film had higher structural stability than did the films with other thicknesses. The preferred (110) orientation of the $\mathrm{MAPbI}_{3}$ layer had superior photoelectric properties because of the improved crystalline quality.

Good absorption properties in the visible region of the active layer are important. To further understand the light absorption capacity of perovskite layers, we measured the absorption spectra of $\mathrm{MAPbI}_{3}$ layers with different thicknesses annealed at $100^{\circ} \mathrm{C}$. Figure $7 \mathrm{~b}$ shows the absorbance curves of the perovskite layers. The absorbance of the perovskite film increased with increasing thickness. The highest absorbance was obtained with a $192 \mathrm{~nm}$ thick perovskite layer. When the thickness of the perovskite film exceeded $192 \mathrm{~nm}$, the previous AFM and XRD measurements showed an increase in surface roughness and a decrease in crystallinity. 


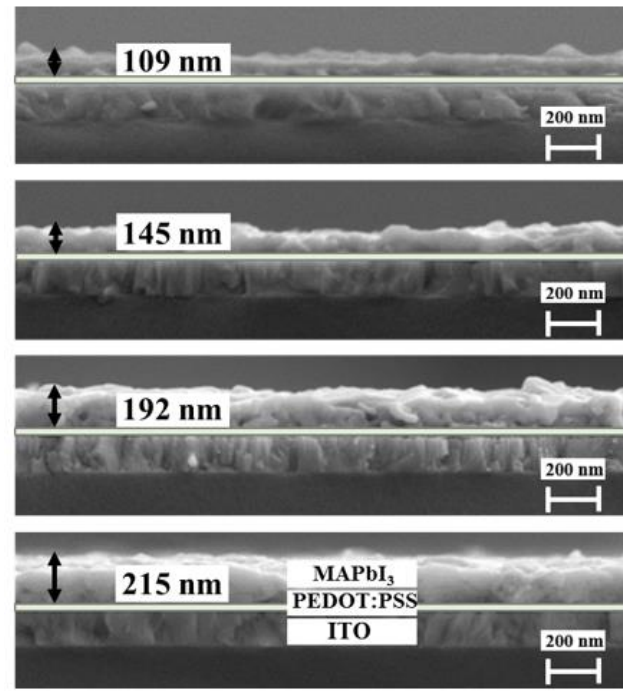

(a)

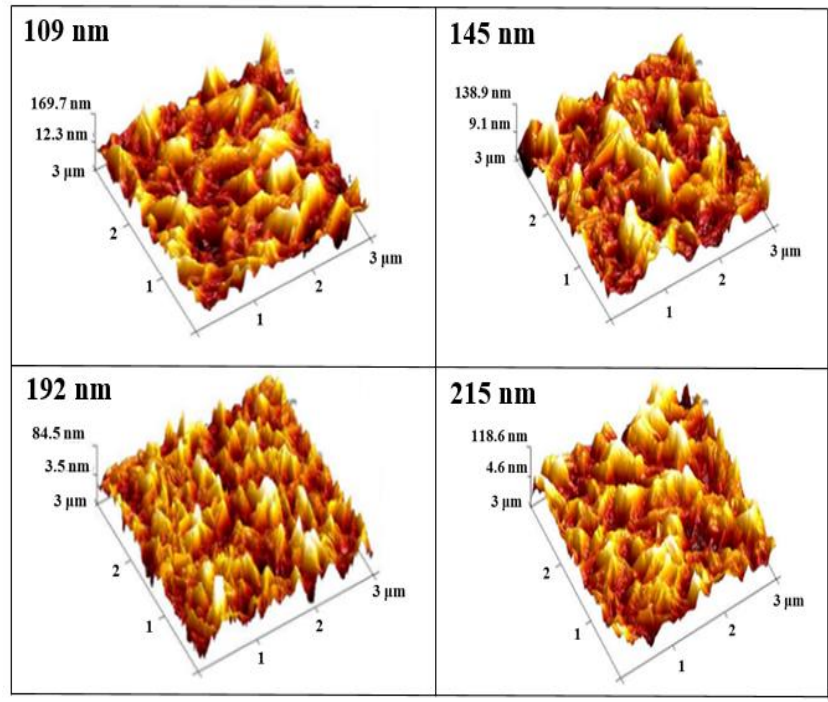

(b)

Figure 6. (a) Cross-sectional SEM images and (b) AFM images of $\mathrm{MAPbI}_{3}$ layer with different thicknesses at an annealing temperature $100{ }^{\circ} \mathrm{C}$.

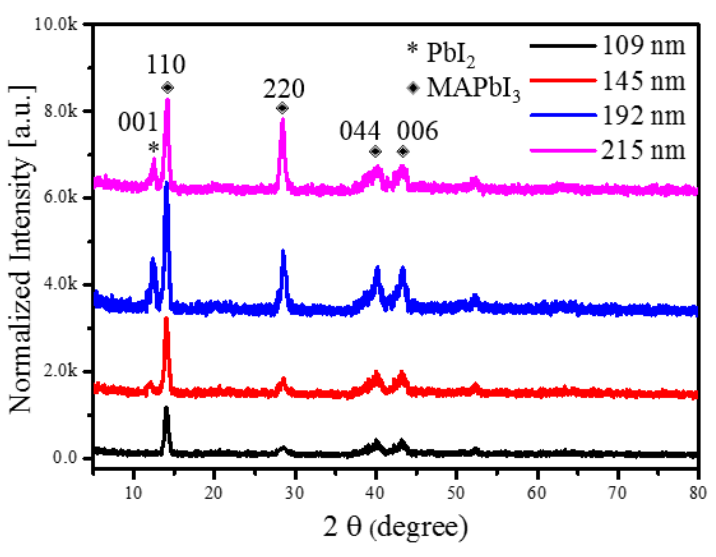

(a)

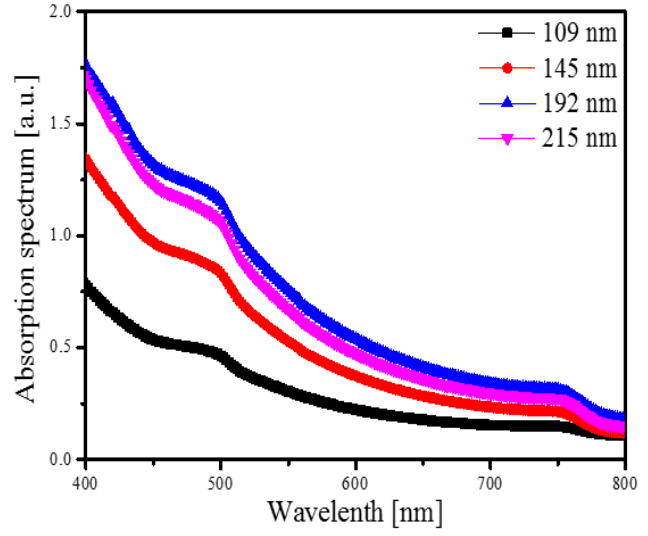

(b)

Figure 7. (a) XRD patterns and (b) absorption spectra of $\mathrm{MAPbI}_{3}$ layer with different thicknesses at an annealing temperature $100{ }^{\circ} \mathrm{C}$.

To investigate the photovoltaic properties of the detectors with different thicknesses of the $\mathrm{MAPbI}_{3}$ layer, we measured the current density-voltage $(\mathrm{J}-\mathrm{V})$ characteristics using the solar simulator and electrometer mentioned in Section 2.3. The J-V curves of the detectors with different thicknesses of perovskite layers are shown in Figure $8 \mathrm{a}$, and parameters such as Jsc and Rs extracted from the J-V curves are listed in Table 2. The maximum $\mathrm{JSC}_{\mathrm{SC}}$ of $18.78 \mathrm{~mA} / \mathrm{cm}^{2}$ and the minimum series resistance of $172.23 \Omega$ were obtained with a film thickness of $192 \mathrm{~nm}$. The optimum thickness of the active layer to improve the detector performance was selected in consideration of the following three phenomena: light-absorption [29], carrier-transport, and carrier-loss characteristics [30]. For example, a mismatch between the carrier diffusion-length and the active layer thickness can lead to a decrease in the current density $(\mathrm{J})$ through carrier-loss. 


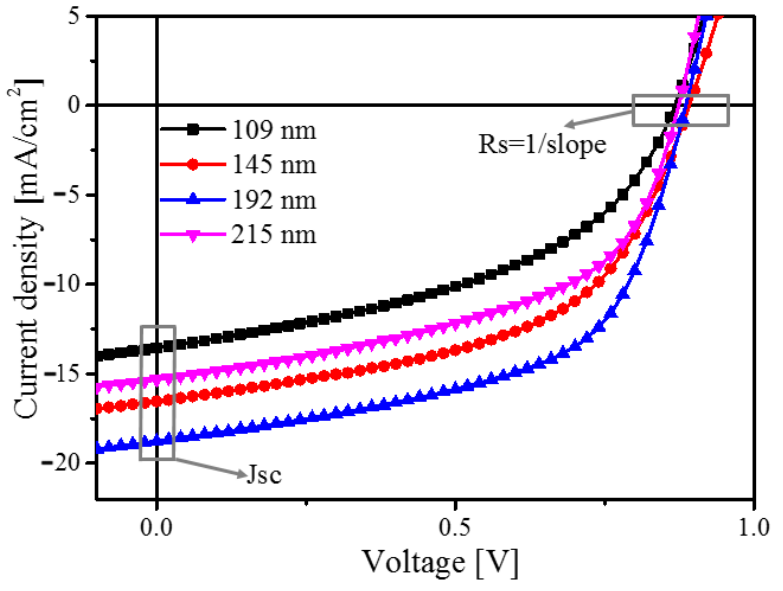

(a)

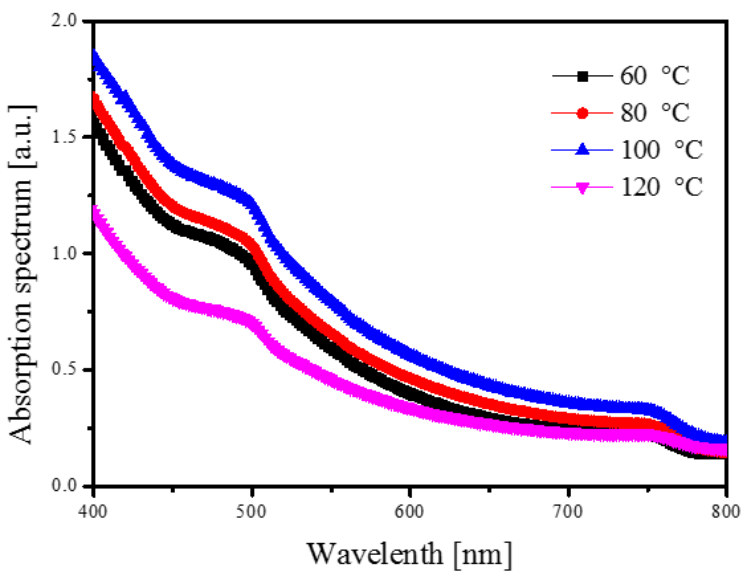

(b)

Figure 8. (a) Current density-voltage (J-V) characteristics of the detectors based on a $\mathrm{MAPbI}_{3}$ layer annealed at temperature $100{ }^{\circ} \mathrm{C}$, and (b) curve fitting of the logarithmic $\mathrm{J}-\mathrm{V}$ characteristics of the detectors in the dark.

Table 2. $\mathrm{J}_{\mathrm{SC}}, \mathrm{R}_{\mathrm{S}}$ and mobility of the detector based on $\mathrm{MAPbI}_{3}$ layer with different thicknesses at an annealing temperature $100^{\circ} \mathrm{C}$.

\begin{tabular}{cccc}
\hline Layer Thickness $[\mathrm{nm}]$. & JSC $\left[\mathrm{mA} / \mathbf{c m}^{2}\right]$ & Rs $[\Omega]$ & Mobility $\left[\mathrm{cm}^{2} / \mathrm{V} \cdot \mathbf{s}\right]$ \\
\hline 109 & $13.56 \pm 0.63$ & $282.11 \pm 3.9$ & $(1.21 \pm 0.06) \times 10^{-4}$ \\
145 & $16.54 \pm 0.61$ & $198.36 \pm 3.8$ & $(1.97 \pm 0.04) \times 10^{-4}$ \\
192 & $18.78 \pm 0.58$ & $172.23 \pm 3.9$ & $(2.84 \pm 0.04) \times 10^{-4}$ \\
215 & $15.32 \pm 0.62$ & $256.09 \pm 3.8$ & $(1.83 \pm 0.05) \times 10^{-4}$ \\
\hline
\end{tabular}

Figure $8 \mathrm{~b}$ shows the logarithmic J-V characteristics of the detectors with different thicknesses of the perovskite layers. The effect of perovskite thickness on detector performance was studied by analyzing carrier mobility. The carrier mobility was determined using the space-charge-limited-current (SCLC) method in the dark [31], and using the modified Mott-Gurney equation, as shown below:

$$
\mu=\frac{8}{9} \cdot J \cdot \frac{L^{3}}{V_{a}^{2} \cdot \varepsilon_{0} \cdot \varepsilon_{r}}
$$

where $\varepsilon_{0}$ is the permittivity of free space, $\varepsilon_{r}$ is the relative permittivity of the perovskite layer, $V_{a}$ is the voltage applied across the detector, $\mu$ is the carrier mobility, and $L$ is the thickness of the perovskite layer. The calculated mobility listed in Table 2 was $1.21 \times 10^{-4}, 1.97 \times 10^{-4}, 2.83 \times 10^{-4}$, and $1.83 \times 10^{-4} \mathrm{~cm}^{2} / \mathrm{Vs}$ for the detectors with perovskite layers with thicknesses of 109, 145, 192 and $215 \mathrm{~nm}$, respectively. For example, Li. et al. successfully prepared a solar cell with a $\mathrm{MAPbI}_{3}$ active layer, and obtained SCLC mobility of $1.90 \times 10^{-4} \mathrm{~cm}^{2} / \mathrm{Vs}$ [32]. As the thickness of the perovskite film increased, the carrier mobility increased. When the thickness of the perovskite film exceeded the optimal $192 \mathrm{~nm}$ thickness, the surface roughness increased and the peak of the (110) plane decreased. The mobility along the (100) direction was larger than the mobility along (001) or other directions [33], which contributed to the formation of a short migration path and increased charge extraction and collection.

We used the X-ray generator and electrometer mentioned in Section 2.3 to study the radiation properties of the detectors with different thicknesses of the $\mathrm{MAPbI}_{3}$ layer. With the scintillator-decoupled detector under artificial solar exposure, the JSC was obtained via the $0 \mathrm{~V}$ bias of the J-V curves. We found the $\mathrm{J}_{\mathrm{SC}}$ to be $13.56,16.54,18.78$ and $15.32 \mathrm{~mA} / \mathrm{cm}^{2}$ for the $X$-ray detectors with perovskite layers with thicknesses of 109, 145, 192, and 215 nm, respectively, as indicated in Figure 9 (left axis). We calculated the CCD and sensitivity using Equations (1) and (2) in Section 2.3. The X-ray detectors with 109, 145, 192 , and $215 \mathrm{~nm}$ thick perovskite layers exhibited sensitivities of 2.11, 2.33, 2.84, and 2.19 mA/Gycm², 
respectively (right axis in Figure 9). The highest sensitivity, i.e., $2.84 \mathrm{~mA} / \mathrm{Gycm}^{2}$, under X-ray exposure was achieved with the detector with a $192 \mathrm{~nm}$ thick perovskite layer. Starkenburg et al. successfully prepared an X-ray detector based on a boron subphthalcyanine chloride (SubPc):PC60BM active layer combined with a CsI scintillator, and obtained a sensitivity of $0.96 \mathrm{~mA} / \mathrm{Gycm}^{2}$ at a bias voltage of $1 \mathrm{~V}$ [34]. High sensitivity was obtained from the detector by applying the optimal conditions of annealing temperature and thickness, thereby improving the surface roughness, increasing the light absorption capacity, improving mobility, and improving the recombination loss of the perovskite layer.

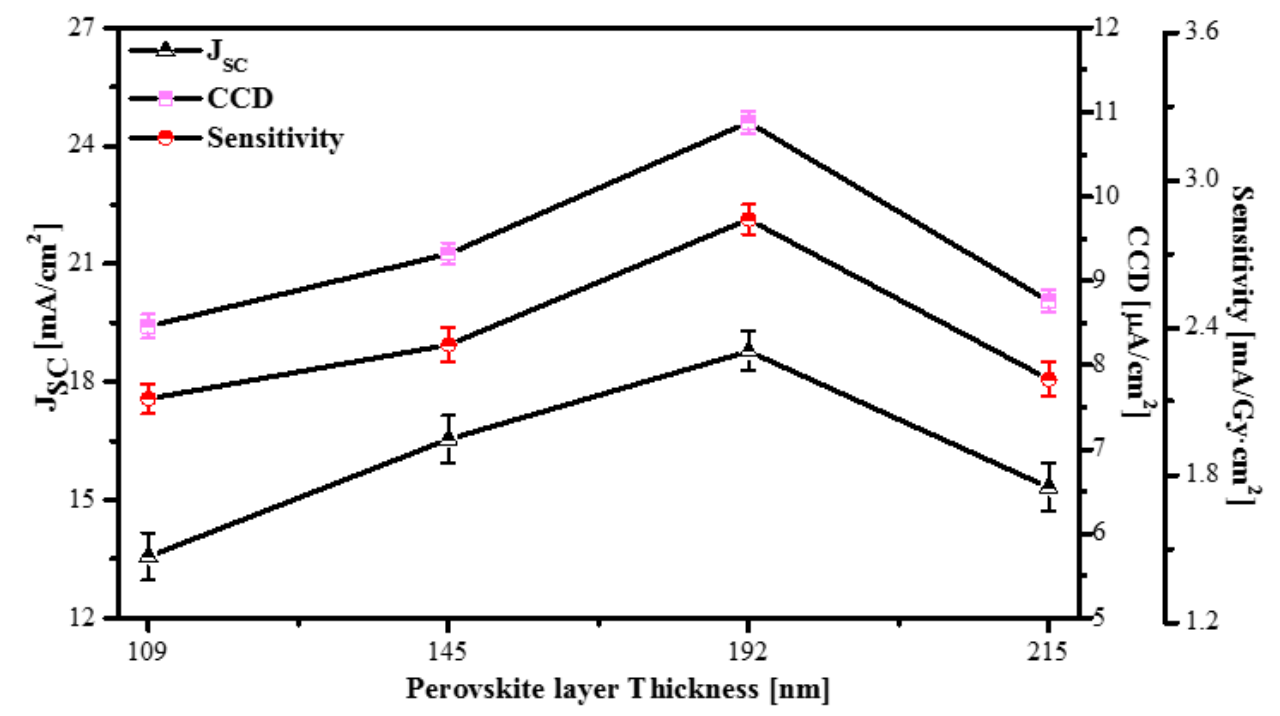

Figure 9. $\mathrm{J}_{\mathrm{SC}}, \mathrm{CCD}$, and sensitivity of the detector based on $\mathrm{MAPbI}_{3}$ layer with different thicknesses at an annealing temperature $100^{\circ} \mathrm{C}$. Error bars represent the standard deviation based on 10 devices per condition.

\section{Conclusions}

In this paper, we investigated a high-sensitivity $X$-ray detector with a perovskite active layer for indirect $X$-ray detection. By changing the annealing temperature and film thickness, we could optimize the electronic and optical properties of the perovskite film applied to the active layer of the detector. First, we studied the structural properties of the $\mathrm{MAPbI}_{3}$ films prepared with different annealing temperatures $\left(60,80,100\right.$, and $\left.120^{\circ} \mathrm{C}\right)$. The $\mathrm{MAPbI}_{3}$ film showed the highest crystallinity and absorption intensity with an annealing temperature of $100{ }^{\circ} \mathrm{C}$. The detector with the $100{ }^{\circ} \mathrm{C}$ annealed perovskite film as the active layer had better photoelectric properties than the detector with the films annealed at other temperatures. Second, by studying the characteristics of different thicknesses $(109,145,192$ and $215 \mathrm{~nm})$ of the perovskite layer, we found that the $192 \mathrm{~nm}$ thick layer had lowest roughness and better mobility. The detector with the perovskite layer that was $192 \mathrm{~nm}$ thick had better current density because of its high light-harvesting efficiency, long electron-hole diffusion length, and less carrier-recombination loss. Finally, the highest sensitivity, i.e., $2.84 \mathrm{~mA} / \mathrm{Gycm}^{2}$, was obtained using the detector with the optimized perovskite layer. Given the many interesting properties of perovskite, such as its low-cost solution processability, highly efficient light absorption, long electron-hole diffusion length, and high carrier mobility, $\mathrm{MAPbI}_{3}$ is a promising candidate for use as an active layer applied to X-ray detectors.

Supplementary Materials: The following are available online at http://www.mdpi.com/1424-8220/20/23/6872/s1.

Author Contributions: Conceptualization, J.K.; formal analysis, H.L., J.L. and J.K.; investigation, H.L., J.L. and J.K.; data curation, H.L. and J.K.; writing-original draft preparation, H.L.and J.L.; writing-review and editing, H.L. and J.K.; visualization, H.L.; supervision, J.K.; project administration, J.K.; All authors have read and agreed to the published version of the manuscript.

Funding: This research received no external funding. 
Conflicts of Interest: The authors declare no conflict of interest.

\section{References}

1. Eames, C.; Frost, J.M.; Barnes, P.R.; O'regan, B.C.; Walsh, A.; Islam, M.S. Ionic transport in hybrid lead iodide perovskite solar cells. Nat. Commun. 2015, 6, 7497. [CrossRef]

2. Roose, B.; Wang, Q.; Abate, A. The role of charge selective contacts in perovskite solar cell stability. Adv. Energy Mater. 2019, 9, 1803140. [CrossRef]

3. Dou, L.; Yang, Y.M.; You, J.; Hong, Z.; Chang, W.H.; Li, G.; Yang, Y. Solution-processed hybrid perovskite photodetectors with high detectivity. Nat. Commun. 2014, 5, 5404. [CrossRef] [PubMed]

4. $\quad$ Chen, L.C.; Lee, K.L.; Lee, K.Y.; Huang, Y.W.; Lin, R.M. Study of Metal-Semiconductor-Metal $\mathrm{CH}_{3} \mathrm{NH}_{3} \mathrm{PbBr}_{3}$ Perovskite Photodetectors Prepared by Inverse Temperature Crystallization Method. Sensors 2020, $20,297$. [CrossRef] [PubMed]

5. Lin, K.; Xing, J.; Quan, L.N.; de Arquer, F.P.G.; Gong, X.; Lu, J.; Li, W. Perovskite light-emitting diodes with external quantum efficiency exceeding 20 percent. Nature 2018, 562, 245-248. [CrossRef] [PubMed]

6. Lee, S.Y.; Kim, S.H.; Nam, Y.S.; Yu, J.C.; Lee, S.; Kim, D.B.; Jung, E.D.; Woo, J.H.; Ahn, S.; Lee, S.; et al. Flexibility of semitransparent perovskite light-emitting diodes investigated by tensile properties of the perovskite layer. Nano Lett. 2019, 19, 971-976. [CrossRef] [PubMed]

7. Yu, W.; Li, F.; Yu, L.; Niazi, M.R.; Zou, Y.; Corzo, D.; Buttner, U. Single crystal hybrid perovskite field-effect transistors. Nat. Commun. 2018, 9, 1-10. [CrossRef]

8. Chin, X.Y.; Cortecchia, D.; Yin, J.; Bruno, A.; Soci, C. Lead iodide perovskite light-emitting field-effect transistor. Nat. Commun. 2015, 6, 7383. [CrossRef]

9. Choi, H.; Mai, C.K.; Kim, H.B.; Jeong, J.; Song, S.; Bazan, G.C.; Heeger, A.J. Conjugated polyelectrolyte hole transport layer for inverted-type perovskite solar cells. Nat. Commun. 2015, 6, 7348. [CrossRef]

10. Wang, D.L.; Cui, H.J.; Hou, G.J.; Zhu, Z.G.; Yan, Q.B.; Su, G. Highly efficient light management for perovskite solar cells. Sci. Rep. 2016, 6, 18922. [CrossRef]

11. Ning, W.; Wang, F.; Wu, B.; Lu, J.; Yan, Z.; Liu, X.; Hultman, L. Long Electron-Hole Diffusion Length in High-Quality Lead-Free Double Perovskite Films. Adv. Mater. 2018, 30, 1706246. [CrossRef] [PubMed]

12. Oga, H.; Saeki, A.; Ogomi, Y.; Hayase, S.; Seki, S. Improved understanding of the electronic and energetic landscapes of perovskite solar cells: High local charge carrier mobility, reduced recombination, and extremely shallow traps. J. Am. Chem. Soc. 2014, 136, 13818-13825. [CrossRef] [PubMed]

13. Zhang, F.; Wang, Z.; Zhu, H.; Pellet, N.; Luo, J.; Yi, C.; Liu, X.; Liu, H.; Wang, S.; Li, X.; et al. Over 20\% PCE perovskite solar cells with superior stability achieved by novel and low-cost hole-transporting materials. Nano Energy 2017, 41, 469-475. [CrossRef]

14. Yang, D.; Sano, T.; Yaguchi, Y.; Sun, H.; Sasabe, H.; Kido, J. Achieving 20\% Efficiency for Low-Temperature-Processed Inverted Perovskite Solar Cells. Adv. Funct. Mater. 2019, 29, 1807556. [CrossRef]

15. Tsai, H.; Liu, F.; Shrestha, S.; Fernando, K.; Tretiak, S.; Scott, B.; Vo, D.T.; Strzalka, J.; Nie, W. A sensitive and robust thin-film x-ray detector using 2D layered perovskite diodes. Sci. Adv. 2020, 6, eaay0815. [CrossRef]

16. Thirimanne, H.M.; Jayawardena, K.D.G.I.; Parnell, A.J.; Bandara, R.M.I.; Karalasingam, A.; Pani, S.; Huerdler, J.E.; Lidzey, D.G.; Tedde, S.F.; Nisbet, A.; et al. High sensitivity organic inorganic hybrid X-ray detectors with direct transduction and broadband response. Nat. Commun. 2018, 9, 1-10. [CrossRef]

17. Gill, H.S.; Elshahat, B.; Kokil, A.; Li, L.; Mosurkal, R.; Zygmanski, P.; Sajo, E.; Kumar, J. Flexible perovskite based X-ray detectors for dose monitoring in medical imaging applications. Phys. Med. 2018, 5, $20-23$. [CrossRef]

18. Wei, H.; Huang, J. Halide lead perovskites for ionizing radiation detection. Nat. Commun. 2019, $10,1066$. [CrossRef]

19. Yakunin, S.; Sytnyk, M.; Kriegner, D.; Shrestha, S.; Richter, M.; Matt, G.J.; Heiss, W. Detection of X-ray photons by solution-processed lead halide perovskites. Nat. Photonics 2015, 9, 444-449. [CrossRef]

20. Shrestha, S.; Fischer, R.; Matt, G.J.; Feldner, P.; Michel, T.; Osvet, A.; Tedde, S.F. High-performance direct conversion X-ray detectors based on sintered hybrid lead triiodide perovskite wafers. Nat. Photonics 2017, 11, 436-440. [CrossRef] 
21. Salim, T.; Sun, S.; Abe, Y.; Krishna, A.; Grimsdale, A.C.; Lam, Y.M. Perovskite-based solar cells: Impact of morphology and device architecture on device performance. J. Mater. Chem. A 2015, 3, 8943-8969. [CrossRef]

22. Li, Y.; Ji, L.; Liu, R.; Zhang, C.; Mak, C.H.; Zou, X.; Shen, H.H.; Leu, S.Y.; Hsu, H.Y. A review on morphology engineering for highly efficient and stable hybrid perovskite solar cells. J. Mater. Chem. A 2018, 6, 12842-12875. [CrossRef]

23. Wu, J.; Zhang, W.; Wang, Q.; Liu, S.; Du, J.; Mei, A.; Rong, Y.; Hu, Y.; Han, H. A favored crystal orientation for efficient printable mesoscopic perovskite solar cells. J. Mater. Chem. A 2020, 8, 11148-11154. [CrossRef]

24. Muscarella, L.A.; Hutter, E.M.; Sanchez, S.; Dieleman, C.D.; Savenije, T.J.; Hagfeldt, A.; Saliba, M.; Ehrler, B. Crystal orientation and grain size: Do they determine optoelectronic properties of MAPbI3 perovskite? J. Phys. Chem. Lett. 2019, 10, 6010-6018. [CrossRef] [PubMed]

25. Motta, C.; El-Mellouhi, F.; Kais, S.; Tabet, N.; Alharbi, F.; Sanvito, S. Revealing the role of organic cations in hybrid halide perovskite $\mathrm{CH}_{3} \mathrm{NH}_{3} \mathrm{PbI}_{3}$. Nat. Commun. 2015, 6, 7026. [CrossRef] [PubMed]

26. Dualeh, A.; Tétreault, N.; Moehl, T.; Gao, P.; Nazeeruddin, M.K.; Grätzel, M. Effect of annealing temperature on film morphology of organic-inorganic hybrid pervoskite solid-state solar cells. Adv. Funct. Mater. 2014, 24, 3250-3258. [CrossRef]

27. Tsai, H.; Asadpour, R.; Blancon, J.C.; Stoumpos, C.C.; Even, J.; Ajayan, P.M.; Kanatzidis, M.G.; Alam, M.A.; Mohite, A.D.; Nie, W. Design principles for electronic charge transport in solution-processed vertically stacked 2D perovskite quantum wells. Nat. Commun. 2018, 9, 1-9. [CrossRef]

28. Ahn, S.; Jang, W.; Park, S.; Wang, D.H. Dry-Stamping-Transferred PC ${ }_{71}$ BM Charge Transport Layer via an Interface-Controlled Polyurethane Acrylate Mold Film for Efficient Planar-Type Perovskite Solar Cells. ACS Appl. Mater. Interfaces 2017, 9, 15623-15630. [CrossRef]

29. Wei, J.; Xu, R.P.; Li, Y.Q.; Li, C.; Chen, J.D.; Zhao, X.D.; Tang, J.X. Enhanced light harvesting in perovskite solar cells by a bioinspired nanostructured back electrode. Adv. Energy Mater. 2017, 7, 1700492. [CrossRef]

30. Wolff, C.M.; Caprioglio, P.; Stolterfoht, M.; Neher, D. Nonradiative Recombination in Perovskite Solar Cells: The Role of Interfaces. Adv. Mater. 2019, 31, 1902762. [CrossRef]

31. Moiz, S.A.; Khan, I.A.; Younis, W.A.; Karimov, K.S. Space Charge-Limited Current Model for Polymers. Conduct. Polym. 2016, 5, 91

32. Li, J.; Jiu, T.; Duan, C.; Wang, Y.; Zhang, H.; Jian, H.; Zhao, Y.; Wang, N.; Huang, C.; Li, Y. Improved electron transport in $\mathrm{MAPbI}_{3}$ perovskite solar cells based on dual doping graphdiyne. Nano Energy 2018, 46, 331. [CrossRef]

33. Zhang, B.; Zhang, M.J.; Pang, S.P.; Huang, C.S.; Zhou, Z.M.; Wang, D.; Cui, G.L. Carrier transport in $\mathrm{CH}_{3} \mathrm{NH}_{3} \mathrm{PbI}_{3}$ films with different thickness for perovskite solar cells. Adv. Mater. Interfaces 2016, 3, 1600327. [CrossRef]

34. Starkenburg, D.J.; Johns, P.M.; Baciak, J.E.; Nino, J.C.; Xue, J. Thin film organic photodetectors for indirect X-ray detection demonstrating low dose rate sensitivity at low voltage operation. J. Appl. Phys. 2017, 122, 225502. [CrossRef]

Publisher's Note: MDPI stays neutral with regard to jurisdictional claims in published maps and institutional affiliations.

(C) 2020 by the authors. Licensee MDPI, Basel, Switzerland. This article is an open access article distributed under the terms and conditions of the Creative Commons Attribution (CC BY) license (http://creativecommons.org/licenses/by/4.0/). 